\title{
Pt nanocrystals formed by ion implantation: A defect-mediated nucleation process
}

\author{
R. Giulian, ${ }^{\text {a) }}$ P. Kluth, L. L. Araujo, D. J. Llewellyn, and M. C. Ridgway \\ Department of Electronic Materials Engineering, Research School of Physical Sciences and Engineering, \\ Australian National University, Canberra ACT 0200, Australia
}

(Received 3 June 2007; accepted 7 August 2007; published online 29 August 2007)

\begin{abstract}
The influence of ion irradiation of $\mathrm{SiO}_{2}$ on the size of metal nanocrystals (NCs) formed by ion implantation has been investigated. Thin $\mathrm{SiO}_{2}$ films were irradiated with high-energy Ge ions then implanted with Pt ions. Without Ge irradiation, the largest Pt NCs were observed beyond the Pt projected range. With irradiation, Ge-induced structural modification of the $\mathrm{SiO}_{2}$ layer yielded a decrease in Pt NC size with increasing Ge fluence at such depths. A defect-mediated NC nucleation mechanism is proposed and a simple yet effective means of modifying and controlling the Pt NC size is demonstrated. (c) 2007 American Institute of Physics. [DOI: 10.1063/1.2777165]
\end{abstract}

Amorphous $\mathrm{SiO}_{2}$ is widely used in the fabrication of micro- and optoelectronic devices. Though this material has been the subject of intensive study, some details of the structural modifications induced by ion irradiation remain unclear. ${ }^{1,2}$ Examples of irradiation-induced modification include compaction of the implanted layer ${ }^{3}$ due to changes in the bond-angle and bond-length distributions and the formation of defect configurations including $\mathrm{O}$-vacancy centers and nonbridging O-hole centers. ${ }^{4-7}$ Such processes are dominated by nuclear stopping or elastic interactions between the incident ion and target nuclei. At high irradiation energies, where the energy loss is dominated by electronic stopping or inelastic interactions between the incident ion and target electrons, additional irradiation-induced structural modifications can include anisotropic plastic deformation ${ }^{8}$ and latent track formation. ${ }^{9}$

The use of amorphous $\mathrm{SiO}_{2}$ as a host material for metal nanocrystals (NCs) is also well established. Examples include $\mathrm{SiO}_{2}$ encapsulation after NC formation ${ }^{10}$ as well as $\mathrm{NC}$ formation within $\mathrm{SiO}_{2}$ by ion implantation. ${ }^{11,12}$ Advantages of the latter include controlling the depth and concentration of the implanted metal atoms and the protection afforded the NCs against oxidizing or corrosive environments. ${ }^{12}$ Ion irradiation of the $\mathrm{SiO}_{2}$ matrix subsequent to metal $\mathrm{NC}$ formation represents a means of altering the NC size distributions ${ }^{13-15}$ to better suit specific applications. In general, such applications are governed by the unique optical, ${ }^{16}$ catalytic,${ }^{17}$ and therapeutic ${ }^{18}$ properties of metal NCs that can differ dramatically from those of their bulk counterparts. ${ }^{19}$ Finite size effects and the high proportion of surface atoms in a NC are responsible for these differences.

In this study, we investigate how defects produced in amorphous $\mathrm{SiO}_{2}$ by ion irradiation prior to metal $\mathrm{NC}$ formation can subsequently influence the size of Pt NCs formed by ion implantation. (We note that $\mathrm{Pt} \mathrm{NC}$ formation in $\mathrm{SiO}_{2}$ has received scant attention in the literature.) High-energy Ge ion irradiation was used to generate a constant defect distribution over the extent of a thin $\mathrm{SiO}_{2}$ layer. Pt ions were then implanted into the structurally modified $\mathrm{SiO}_{2}$ layer and the size evolution of $\mathrm{Pt} \mathrm{NCs}$ was measured as a function of the Ge-ion fluence. We show that Ge-ion irradiation yielded a

${ }^{a)}$ Electronic mail: raq109@rsphysse.anu.edu.au significant reduction in mean Pt NC diameter and thus demonstrate a simple means of controlling the Pt NC size.

$5 \mathrm{MeV}$ Ge ions were implanted into amorphous, $\sim 1.9 \mu \mathrm{m}$ thick $\mathrm{SiO}_{2}$ films [thermally grown on (100) Si substrates] at liquid $\mathrm{N}_{2}$ temperature with ion fluences at the name of $(1-50) \times 10^{15}$ ions $/ \mathrm{cm}^{2}$. Samples were then implanted with 4.5 MeV Pt ions, again at liquid $\mathrm{N}_{2}$ temperature, to a fluence of $1 \times 10^{17}$ ions $/ \mathrm{cm}^{2}$. Following implantation, samples were annealed in forming gas $\left(95 \% \mathrm{~N}_{2} / 5 \%\right.$ $\mathrm{H}_{2}$ ) for $1 \mathrm{~h}$ at $1100{ }^{\circ} \mathrm{C}$ to promote $\mathrm{NC}$ growth.

The depth distributions of irradiated and implanted atoms and the number of vacancies generated by both Ge and Pt ions, as simulated by SRIM $2003,{ }^{20}$ are plotted in Fig. 1 . Clearly, the Ge atoms are located at depths far beyond the $\mathrm{SiO}_{2}$ layer (thus negating impurity effects), while the Pt atomic concentration has a maximum within the $\mathrm{SiO}_{2}$ layer at a depth of approximately $1.4 \mu \mathrm{m} .^{21}$ Vacancy production by $\mathrm{Ge}$ ions is nearly constant over the extent of the $\mathrm{SiO}_{2}$ layer while, as expected, the maximum in Pt-induced vacancy production is at slightly lesser depths $(\sim 1.1 \mu \mathrm{m})$ than the atomic concentration maximum. The Pt atomic depth dis-

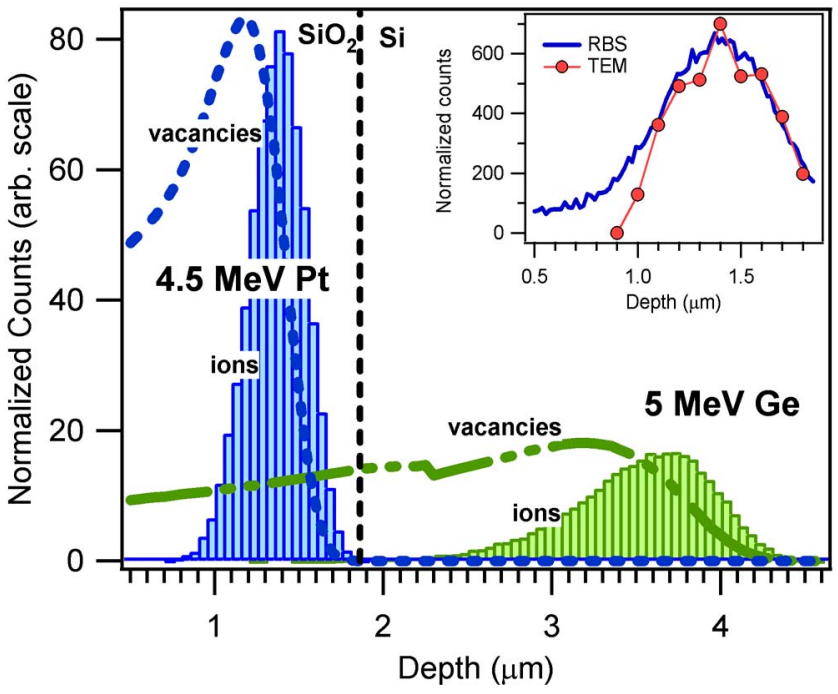

FIG. 1. (Color online) Ge $\left(5 \times 10^{16}\right.$ ions $\left./ \mathrm{cm}^{2}\right)$ and $\mathrm{Pt}\left(1 \times 10^{17}\right.$ ions $\left./ \mathrm{cm}^{2}\right)$ atomic depth distributions and vacancy production as simulated by SRIM. The inset shows the experimental Pt atomic depth distribution determined by RBS and TEM. 


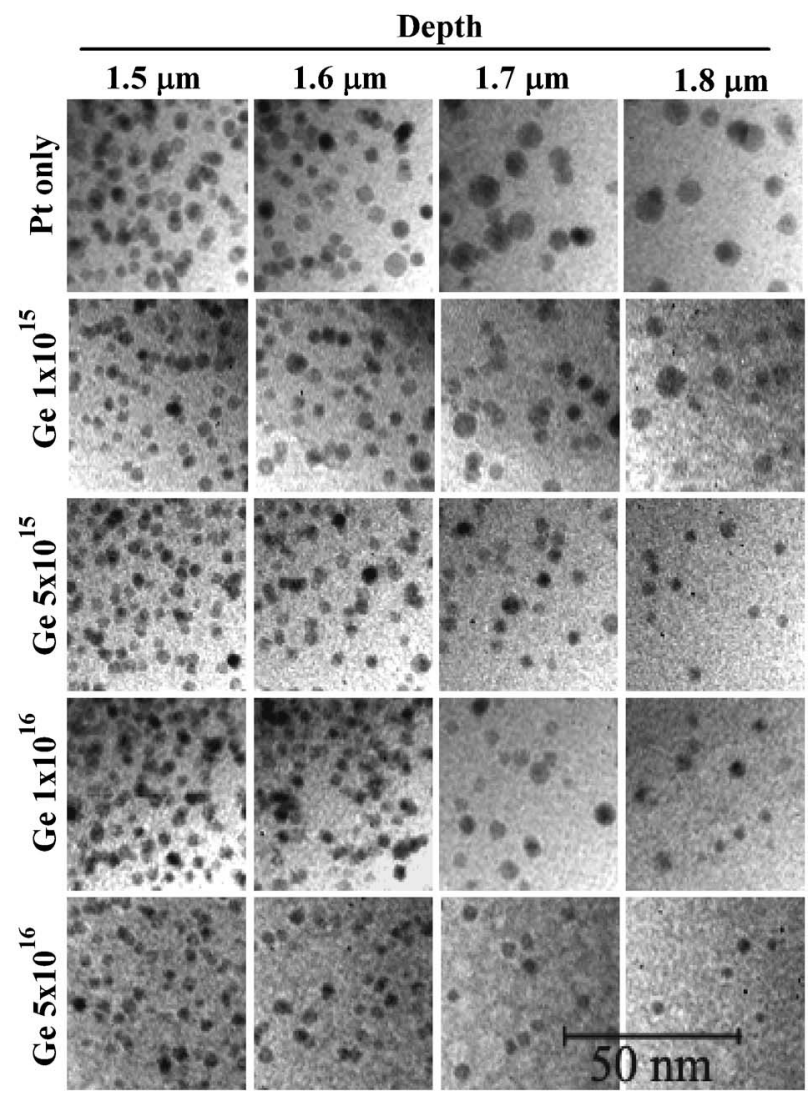

FIG. 2. TEM micrographs of samples implanted with increasing fluences of $5 \mathrm{MeV}$ Ge ions and subsequently implanted with $1 \times 10^{17} \mathrm{Pt} / \mathrm{cm}^{2}$. Images in the same row represent different depths for the same sample.

tribution measured by Rutherford backscattering spectrometry (RBS) and estimated from transmission electron microscopy (TEM) measurements is shown in the figure inset.

Figure 2 displays the representative results obtained by TEM using a Philips CM300 microscope operating at $300 \mathrm{kV}$. The samples were prepared in cross-section geometry with the small-angle cleavage technique. ${ }^{22}$ Images in the same row represent different depths in the same sample, while different samples at the same depths are displayed vertically, with increasing Ge irradiation fluence from top to bottom. The top row shows the sample without Ge irradiation where differences in the NC size as a function of depth are readily apparent. The largest NCs formed at depths of $\sim 1.8 \mu \mathrm{m}$ below the surface, where both the vacancy production and atomic concentration resulting from Pt implantation were the lowest. In the samples first irradiated with Ge ions, the second to fourth rows show a progressively decreasing $\mathrm{NC}$ size with increasing Ge irradiation fluence at depths of 1.6-1.8 $\mu \mathrm{m}$. No significant change in NC size is apparent as a function of fluence at $1.5 \mu \mathrm{m}$ where the vacancy generation due to Pt implantation exceeds that due to Ge irradiation.

Figure 3(a) shows a magnified view of the simulated Pt atomic depth distribution and the vacancy production by both $\mathrm{Ge}$ and $\mathrm{Pt}$ ions, the former corresponding to an irradiation fluence of $5 \times 10^{16} \mathrm{ions} / \mathrm{cm}^{2}$. [RBS measurements (not shown) demonstrated that the Pt atomic depth distribution was not influenced by either the annealing process or $\mathrm{Ge}-$ ion irradiation.] Figure 3(b) shows the mean Pt NC diameter as a function of depth over the same region. For depths of $1.7-1.8 \mu \mathrm{m}$, the mean $\mathrm{NC}$ diameter decreases from Downloaded 26 Śep 2007 to 150.203 .178 .71 . Redistribution subject
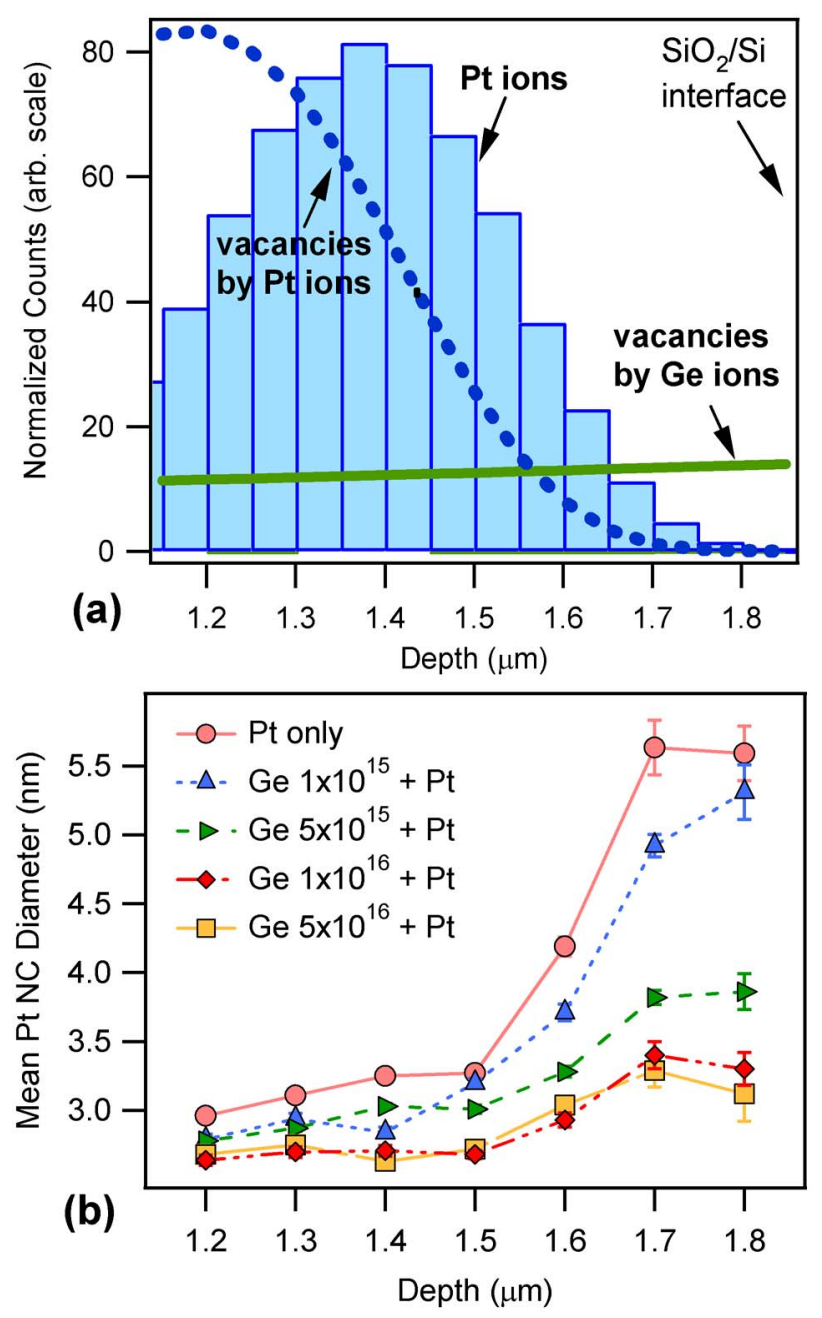

FIG. 3. (Color online) (a) Pt $\left(1 \times 10^{17}\right.$ ions $\left./ \mathrm{cm}^{2}\right)$ atomic depth distribution and vacancy production for Ge irradiation $\left(5 \times 10^{16}\right.$ ions $\left./ \mathrm{cm}^{2}\right)$ and $\mathrm{Pt}$ implantation over depths of $1.2-1.8 \mu \mathrm{m}$ (results simulated by SRIM), and (b) mean Pt NC diameter as functions of depth and Ge irradiation fluence for the same region shown in (a).

$\sim 5.5$ to $\sim 3.5 \mathrm{~nm}$ as the Ge irradiation fluence increases. At lesser depths $(1.2-1.5 \mu \mathrm{m})$, a slight reduction in NC diameter with increasing Ge irradiation fluence is also apparent despite the vacancy production being dominated by Pt ion implantation. This may reflect $\mathrm{Pt} \mathrm{NC}$ nucleation on $\mathrm{Ge}$ irradiation-induced defects during the early stages of the $\mathrm{Pt}$ implantation. Figure 3 thus demonstrates that $\mathrm{Pt}$ NC size is not governed by the $\mathrm{Pt}$ atomic concentration but by nuclear energy deposition.

Figure 4 shows the mean Pt NC diameter as a function of the total energy deposited in vacancy production (Ge irradiation plus Pt implantation using a full cascade simulation) over the $0.1 \mu \mathrm{m}$ depth intervals shown in Fig. 3. Clearly, the mean Pt NC diameter decreases as the total energy deposited in vacancy production increases. The mean diameter saturates at $\sim 3 \mathrm{~nm}$ when the energy deposited in vacancy production exceeds $\sim 2 \times 10^{23} \mathrm{keV} / \mathrm{cm}^{3}$. Figure 4 thus quantifies the correlation between $\mathrm{Pt} \mathrm{NC}$ diameter and nuclear energy deposition. We note that the potential influence of electronic stopping must also be considered. At depths of $\sim 1.7 \mu \mathrm{m}$, SRIM values for the total electronic and nuclear stopping (including both the primary and recoils) of $5 \mathrm{MeV}$ Ge ions incident on $\mathrm{SiO}_{2}$ are $\sim 1.07$ and $0.19 \mathrm{keV} / \mathrm{nm}$, respectively. The former is less than the electronic stopping to AlP license or copyright, see http://apl.aip.org/apl/copyright.jsp 


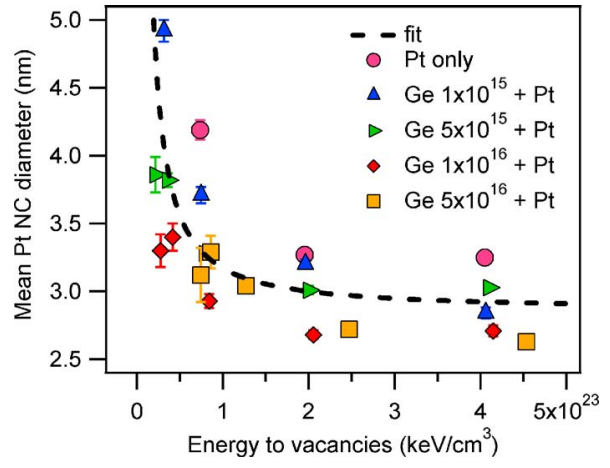

FIG. 4. (Color online) Mean Pt NC diameter as a function of the total energy deposited in vacancy production, the latter is simulated by SRIM.

threshold values required for ion hammering and latent track formation in amorphous $\mathrm{SiO}_{2}(\sim 2 \mathrm{keV} / \mathrm{nm})$ (Ref. 9) and irradiation-induced $\mathrm{NC}$ nucleation in $\mathrm{Cu}$-oxide containing glass $(\sim 5 \mathrm{keV} / \mathrm{nm}){ }^{23}$ Nonetheless, the total energy deposited in electronic stopping processes is, like the total energy deposited in nuclear processes, sufficient to compact the $\mathrm{SiO}_{2}$ layer.

Striking differences are apparent upon a comparison of $\mathrm{Pt}$ NC formation, as presented above, with earlier reports for $\mathrm{Au}$ (Ref. 24) and $\mathrm{Cu}$ (Ref. 25) NC formation. For the latter two metals, the largest NCs are observed at the atomic concentration maximum, in close proximity to the vacancy production maximum. In contrast, the largest Pt NCs observed herein are at the vacancy production minimum (in the absence of $\mathrm{Ge}$ ion irradiation). For comparable metal atomic concentrations and annealing conditions, $\mathrm{Pt}$ NCs are also significantly smaller than both $\mathrm{Au}$ and $\mathrm{Cu} \mathrm{NCs}$, again indicative of differences in the nucleation and/or growth processes. We thus speculate that $\mathrm{Pt} \mathrm{NCs}$ preferentially nucleate on irradiation-induced defects resulting from nuclear energy deposition. A more detailed comparison of NC formation as a function of metal would necessitate consideration of differences in metal diffusivity (in the presence of irradiationinduced disorder), metal solubility, and metal/matrix interfacial energies.

As noted previously, irradiation-induced structural modifications of amorphous $\mathrm{SiO}_{2}$ can be of many forms with examples that include compaction and the formation of O-vacancy centers. However, both the compaction ${ }^{3}$ and $\mathrm{O}$-vacancy center concentration ${ }^{4}$ saturate when the energy deposited in vacancy production exceeds $\sim 10^{20} \mathrm{keV} / \mathrm{cm}^{3}$, three orders of magnitude less than that observed herein for the mean Pt NC diameter. The observations presented in this study are unlikely the result of a single defect configuration but most probably relate to an ensemble of irradiationinduced structural modifications. A final irradiation-induced structural modification for consideration is the potential influence of atoms, both $\mathrm{Si}$ and $\mathrm{O}$, recoiled from the $\mathrm{SiO}_{2}$ layer by Ge-ion irradiation. The resulting imbalance in vacancy/ interstitial concentrations and stoichiometry (both microscopic and macroscopic) may also influence Pt NC nucleation. Furthermore, such effects may not saturate ${ }^{26}$ for the given Ge-ion fluence range.

In summary, we have investigated the influence of ion irradiation of $\mathrm{SiO}_{2}$ on the mean diameter of Pt NCs. Without ion irradiation, the largest Pt NCs $(\sim 5.5 \mathrm{~nm})$ formed at the atomic concentration and vacancy production minima, in contrast to other metals. With ion irradiation prior to $\mathrm{NC}$ formation, the mean Pt NC diameter decreased as the irradiation fluence increased. Saturation of the NC diameter at $\sim 3 \mathrm{~nm}$ was observed when the energy deposited in vacancy production reached $\sim 2 \times 10^{23} \mathrm{keV} / \mathrm{cm}^{3}$. We suggest Pt NCs readily nucleated on irradiation-induced disorder, the nature of which was not identified but was unlikely to be a single defect configuration. High-energy ion irradiation of $\mathrm{SiO}_{2}$ prior to $\mathrm{Pt} \mathrm{NC}$ formation, producing a near-constant concentration of irradiation-induced vacancies over the extent of the $\mathrm{SiO}_{2}$ layer, yielded a much more uniform Pt NC size distribution and thus represents an effective means of tailoring the Pt NC diameter.

The authors thank the Australian Research Council for financial support.

${ }^{1}$ A. C. Wright, B. A. Shakhmatkin, and N. M. Vedishcheva, Glass Phys. Chem. 27, 97 (2001).

${ }^{2}$ R. L. Mozzi and B. E. Warren, J. Appl. Crystallogr. 2, 164 (1969).

${ }^{3}$ C. M. Johnson, M. C. Ridgway, and P. W. Leech, Appl. Phys. Lett. 69, 984 (1996).

${ }^{4}$ R. A. B. Devine, Nucl. Instrum. Methods Phys. Res. B 91, 378 (1994).

${ }^{5}$ R. A. B. Devine and M. H. Debroux, J. Appl. Phys. 54, 4197 (1983).

${ }^{6}$ R. A. B. Devine, Appl. Phys. Lett. 43, 1056 (1983).

${ }^{7}$ R. A. B. Devine and A. Golanski, J. Appl. Phys. 55, 2738 (1984).

${ }^{8}$ A. Benyagoub, S. Loffler, M. Rammensee, S. Klaumunzer, and G. Saemannischenko, Nucl. Instrum. Methods Phys. Res. B 65, 228 (1992).

${ }^{9}$ S. Klaumunzer, Nucl. Instrum. Methods Phys. Res. B 225, 136 (2004).

${ }^{10}$ S. Penner, D. Wang, D. S. Su, G. Rupprechter, R. Podloucky, R. Schlogl, and K. Hayek, Surf. Sci. 532-535, 276 (2003).

${ }^{11}$ G. W. Arnold and J. A. Borders, J. Appl. Phys. 48, 1488 (1977).

${ }^{12}$ A. Meldrum, R. F. Haglund, L. A. Boatner, and C. W. White, Adv. Mater. (Weinheim, Ger.) 13, 1431 (2001).

${ }^{13}$ K. H. Heinig, T. Muller, B. Schmidt, M. Strobel, and W. Moller, Appl. Phys. A: Mater. Sci. Process. 77, 17 (2003).

${ }^{14}$ P. Kluth, B. Johannessen, G. J. Foran, D. J. Cookson, S. M. Kluth, and M. C. Ridgway, Phys. Rev. B 74, 014202 (2006).

${ }^{15}$ G. Rizza, H. Cheverry, T. Gacoin, A. Lamasson, and S. Henry, J. Appl. Phys. 101, 014321 (2007).

${ }^{16}$ Mostafa A. El-Sayed, Acc. Chem. Res. 34, 257 (2001).

${ }^{17}$ A. T. Bell, Science 299, 1688 (2003).

${ }^{18}$ M. E. Akerman, W. C. W. Chan, P. Laakkonen, S. N. Bhatia, and E. Ruoslahti, Proc. Natl. Acad. Sci. U.S.A. 99, 12617 (2002).

${ }^{19}$ A. I. Frenkel, C. W. Hills, and R. G. Nuzzo, J. Phys. Chem. B 105, 12689 (2001).

${ }^{20}$ J. F. Ziegler, J. P. Biersack, and U. Littmark, The Stopping and Range of Ions in Solids (Pergamon, New York, 1985), Vol. 1.

${ }^{21}$ SRIM depth scales for the Pt-induced vacancy production and atomic depth distribution were scaled (increased) to coincide with the experimental determination of the latter using Rutherford backscattering spectrometry and transmission electron microscopy. The as-simulated Pt projected range was $\sim 1.1 \mu \mathrm{m}$ which was then scaled to the experimentally determined value of $\sim 1.4 \mu \mathrm{m}$. We attribute the difference in simulated and experimentally determined distributions to possible inaccuracies in the Pt-ion stopping power used in the simulations. $\mathrm{A} \mathrm{SiO}_{2}$ density of $2.32 \mathrm{~g} / \mathrm{cm}^{3}$ was utilized for both the simulations and experimental determinations.

${ }^{22}$ S. D. Walck and J. P. McCaffrey, Thin Solid Films 308-309, 399 (1997).

${ }^{23}$ E. Valentin, H. Bernas, C. Ricolleau, and F. Creuzet, Phys. Rev. Lett. 86, 99 (2001).

${ }^{24}$ P. Kluth, B. Johannessen, D. J. Cookson, G. J. Foran, and M. C. Ridgway, Nucl. Instrum. Methods Phys. Res. B 246, 30 (2006).

${ }^{25}$ B. Johannessen, P. Kluth, C. J. Glover, G. de M. Azevedo, D. J. Llewellyn, G. J. Foran, and M. C. Ridgway, J. Appl. Phys. 98, 024307 (2005).

${ }^{26}$ S. L. Ellingboe and M. C. Ridgway, Nucl. Instrum. Methods Phys. Res. B 127, 90 (1997). 